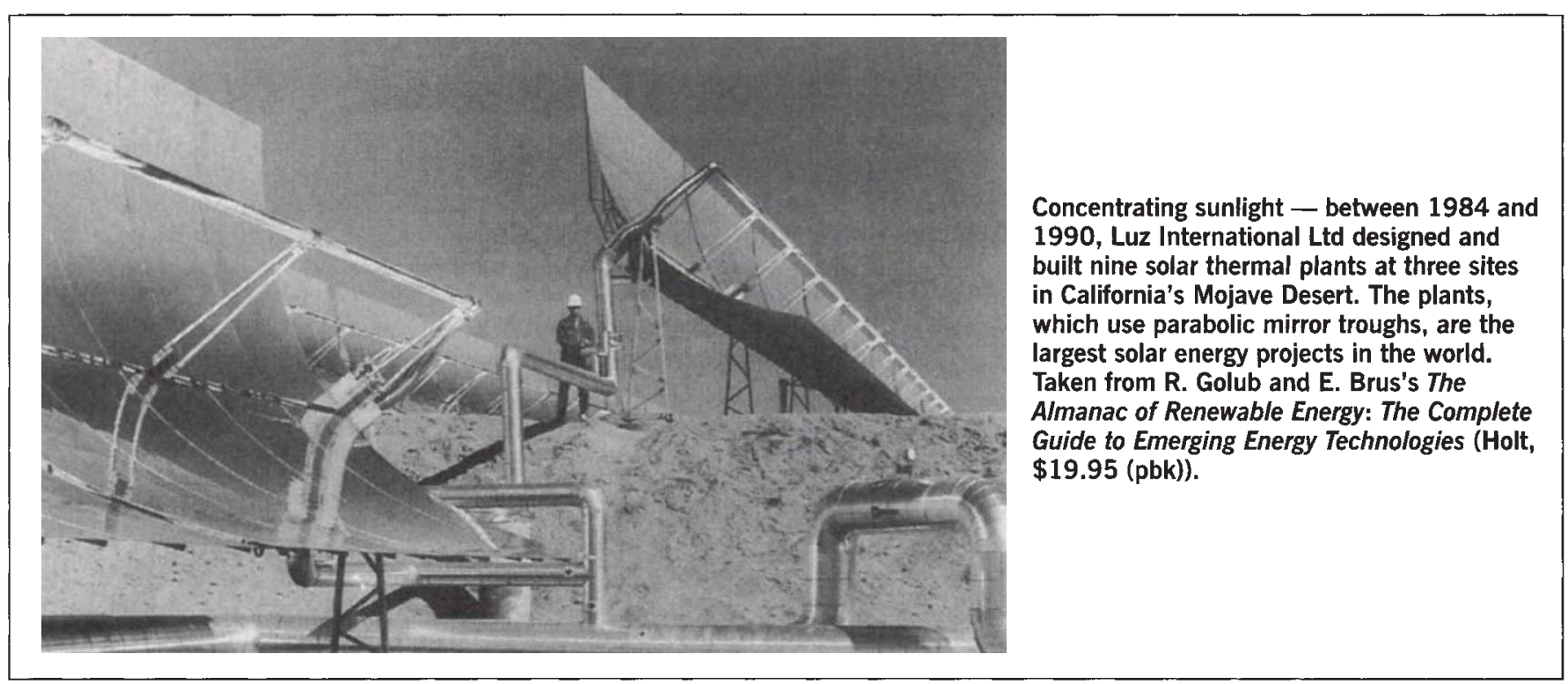

in the first four parts.

With many nations developing biodiversity plans following the UN Conference on Environment and Development held in Rio de Janeiro in 1992, the title Biodiversity and Conservation for a new journal must be right. First published in 1992, the editorial policy is to include both contributed papers and special issues on individual topics. For example, one part in volume 2 contains a collection of seven papers on the theme "peatlands and people". These papers provide an overview of peatland archaeology and palaeoecology, conservation and the use of peatlands industrially and for forestry, but, apart from one paper on botanical diversity, it is difficult to gain an understanding of the biodiversity of peatlands. A similar criticism could be made of other parts of volumes 2 and 3 where "conservation" is the predominant theme and "biodiversity" seems lost in the ecological and conservation studies. Certainly the genetical aspects of biological diversity are poorly represented in the papers, but it is useful to see papers on zoos, cryopreservation of seeds and the economics of nature tourism.

Both journals contain collections of papers and a selection of book reviews. The number of reviews in Biology and the Environment is small, but the review section is clearly lively in Biodiversity and Conservation. Both journals have a few short articles in some of their parts, but these sections of comment, recent discoveries and so on are certainly far from vibrant. With the excitement of conservation, the environment and the interactions of humans with nature, there is still scope for the development of fora that recognize these critical issues as we approach the twenty-first century.

\title{
0 'er the land of the free
}

Jeff Wilson

Land Contamination and Reclamation. Editor D. Davis. EPP, 52 Kings Road, Richmond, Surrey TW10 6EP, UK. 4/yr. United Kingdom £69, elsewhere $£ 79$ (institutional); United Kingdom $£ 35$, elsewhere $£ 45$ (personal).

Public concern about environmental matters shows no sign of slackening. Rather the reverse: there is now much less willingness to tolerate pollution, or the threat of pollution, even when its damaging effects are reckoned to be barely perceptible. Sharp disputes between fishing and forestry interests over the possible consequences of acid deposition on forested catchments in relatively pristine areas of Scotland illustrate this heightened awareness, particularly when it involves problems of contamination of soils.

The state of the environment is of overarching interest to all sectors of society, both urban and rural, impinging as it does on many aspects of community, commercial and political life. This new journal is a successful attempt to provide a wide audience with informed comment on, and indepth analysis of, all aspects of land contamination and remediation. It is definitely not only for specialist environmental scientists; although it contains well researched and extensively referenced articles, there is also an attractive mix of other contributions that will immediately appeal to outsiders. For example, early issues feature authoritative papers on land contamination by chlorinated dioxins and furans, statistical sampling design for contaminated sites, human health risks from ingestion of contaminated soil and the effects of contaminated land on ground water.

There are also several papers, mainly from industrial sources, that have a practical slant and refer extensively to reports by consultancies and agencies. As one might expect, commercial considerations are very much to the fore. Topics covered include stabilization of contaminated soil, soil washing and quality-assurance principles in the survey and analysis of contaminated land. These papers are marked by a complete absence of references to the scientific literature, yet despite - or because - of this they are nonetheless extremely useful from an applied point of view.

A further feature of the journal is the inclusion of notes on current land-remediation projects; news of new equipment, services, courses and conferences; book reviews; clean-up policies in different countries; and reports on the SITE programme of the US Environmental Protection Agency. There is something for everyone in this journal, and it is reasonably priced and well produced. The editor and his advisory board have struck a commendable balance. The stated aim of the journal is "to supplement original research and discussion papers on environmental, technical and public-health issues with full coverage of the commercial and legal context" and in this they have been eminently successful.

Jeff Wilson is in the Division of Soils, Macaulay Land Use Research Institute, Aberdeen AB9 2QJ, UK.

\section{Journal prices}

Details of editors and frequency of publication, and the subscription rates appearing at the top of each review, are given in most instances for 1994. This information may not be complete in all cases. Readers are therefore advised to check prices with the publisher. 